\section{Hyperdipsia after septal and diagonal band of Broca lesions*}

\author{
DAVID A. NOLLEY $\dagger$ \\ Western Michigan University, Kalamazoo, Mich. 49001
}

In rats, anodal lesions were made in the diagonal band of Broca (DBB) in conjunction with lesions centered in either the posterior (PS) or anterior (AS) septal area. AS lesions produced no elevations in intake, while PS lesions enhanced water intake significantly. DBB-lesioned animals raised their water intake sufficiently to mask any functional relationship between the DBB and a specific locus within the septal nuclei.

It appears that anterior septal (AS) hyperdipsia results from lesions which also disrupt responding reinforced by either water or food, which is consistent with a response-inhibition deficit thought to obtain when hippocampal afferents from the brainstem are severed (Carey, 1968). Hyperdipsia resulting from posterior septal (PS) lesions (Lubar, Boyce, \& Schaefer, 1968), however, are unaccompanied by response perseveration (Carey, 1969) or disturbances in osmotic stress (Blass \& Hanson, 1970). The latter disfunction would otherwise implicate this portion of the septal area with the adjacent supraoptic and periventricular hypothalamic mechanisms involved in antidiuretic hormone (ADH) release (Ranson, Fischer, \& Ingram, 1938).

The diagonal band of Broca (DBB) is a ventral continuation of the medial septal nucleus (Fox, 1940) which appears to influence thirst (Carey, 1967; Fisher \& Coury, 1964). The DBB has been shown to participate in hippocampal afferent (Daitz \& Powell, $1954)$ and efferent conduction (Raisman, Cowan, \& Powell, 1966), and, like AS lesions, ablations which invade the DBB appear to contribute to response perseveration (Carey, 1968). The purpose of this study was to clarify the distinction between AS and PS lesions in their effects upon water intake. Lesions of the DBB were performed in conjunction with lesions centered in either the posterior or anterior medial and lateral septal nuclei.

* This research was supported by Grant MH-16995-02 from the Public Health Service and Grant B008580 from the $\mathrm{N}$ ational Science Foundation to Dr. Frederick P. Gault, Western Michigan University. This paper was based upon a thesis submitted in partial fulfillment of the requirements for the MA degree in psychology at Western Michigan University. Preliminary versions were presented before the annual meeting of the Eastern Psychological Association, 1970, and the annual meeting of the Michigan Academy of Sciences, 1970 .

tPresent address: Brain Research Laboratory, 601 University Ave., Syracuse, N.Y. 13210. intervals and the lesions verified, using the method of Guzman-Flores, Alcaraz, \& Fernandez (1963).
Included in the data were groups used as their own controls.

Bilateral electrolytic lesions were produced under pentobarbital anesthesia, using stereotaxically placed electrodes (insect pins, insulated except for $0.5 \mathrm{~mm}$ at the tip) which passed anodal dc through the uninsulated tip. The lesion circuit was completed by a reference electrode clipped to the ear bar. For septal lesions, an angular approach at $13 \mathrm{deg}$ from the vertical was utilized, using the coordinates anterior 7.9 or $7.1 \mathrm{~mm}$, lateral $0.6 \mathrm{~mm}$, and $0.8 \mathrm{~mm}$ above zero (Konig \& Klippel, 1963), with a current of $2.0 \mathrm{~mA}$ for $30 \mathrm{sec}$. For DBB lesions, a 13-deg angular approach to the coordinates anterior $8.0 \mathrm{~mm}$, lateral $0.2 \mathrm{~mm}$, and $2.0 \mathrm{~mm}$ below zero was employed, with a current of $1.0 \mathrm{~mA}$ for $25 \mathrm{sec}$. For sham operates, electrodes were placed at the appropriate coordinates without passing current and then withdrawn. A correction, in coordinates, for growth of the brain was made for the heavier rats used in this study.

\section{RESULTS}

Reconstruction of lesion damage was performed upon 17 of the 23 Ss. In the other 6 brains, all of which had received only DBB lesions, only the area of greatest damage was demarcated. In Ss with septal lesions, there was extensive destruction of the medial nucleus in all cases, bilateral destruction of the anterio;portion of the lateral septal nucleus in 8 animals. and bilateral posterior destruction in 9 Ss. Septal damage commonly invaded the corpus callosum, the nucleus of the stria terminalis, the postcommissural fornix, and the preoptic precommissural fornix. DBB lesions always included the nucleus and tract of the DBB from at least a millimeter ventral to the basal medial septal nucleus and frequently extending into the medial preoptic area and the medial forebrain bundle.

Lesions centered in the AS, following sham $\mathrm{DBB}$ or preoperative baselines, produced no significant elevations in water intake. However, the Ss with PS lesions following sham DBB or preoperative baselines showed,
Table 1

Lesion-Induced Changes in HOH Intake

\begin{tabular}{lllll}
\hline Group & Mean & Group & Mean & p \\
\hline P & 33.52 & S & 33.64 & $>.50$ \\
P & 33.26 & DBB & 49.81 & $<.05^{*}$ \\
S & 33.64 & DBB & 49.81 & $<.01$ \\
AS & 37.02 & DBB & 67.64 & $<.02^{*}$ \\
PS & 47.47 & DBB & 59.71 & $<.05^{*}$ \\
PS-DBB & 59.71 & AS-DBB & 67.64 & $>.05$ \\
P S & 37.58 & AS & 33.92 & $>.05$ \\
P S & 36.10 & PS & 43.70 & $<.01$ \\
\hline
\end{tabular}

Note-Tests are $t$ tests using correlated samples (*) or independent samples. $P$-preoperative, $D B B$-diagonal band of Broca, PS-posterior septal, AS-anterior septal, $S-D B B$ sham. 

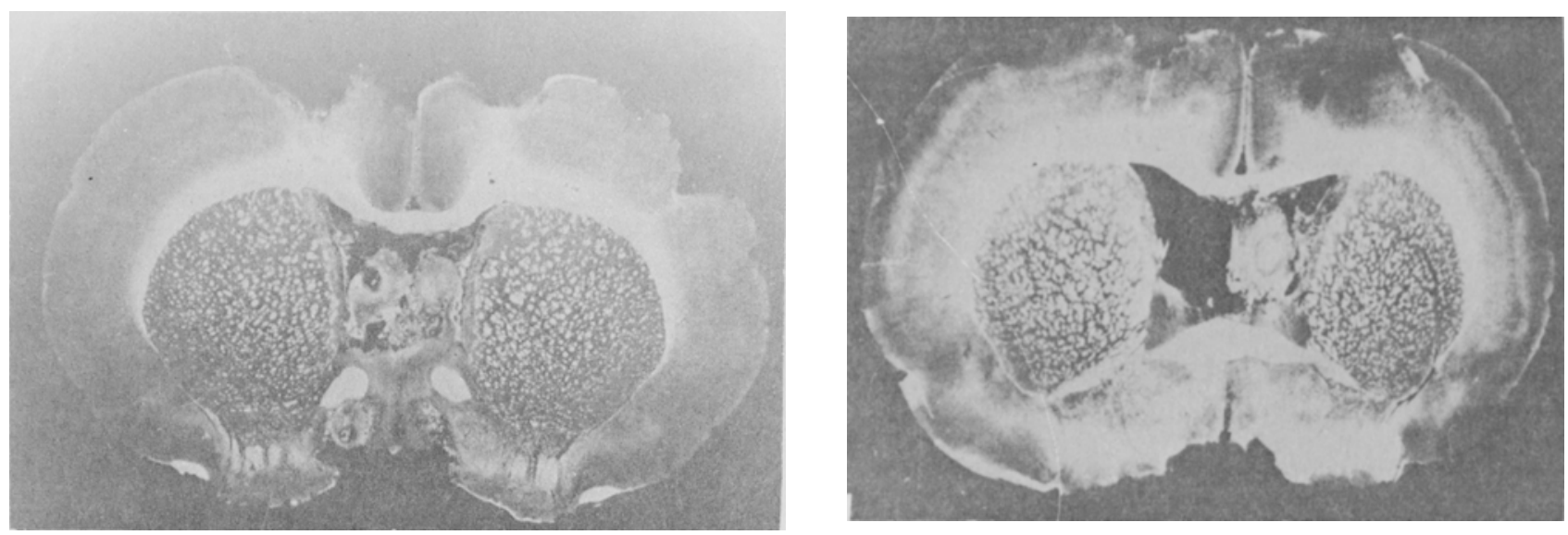

Fig. 1. Representative sections illustrating AS and DBB damage (left) and PS damage (right).

until sacrifice, significantly increased mean intake.

All Ss with DBB lesions increased water intake significantly. The increase was so great that it overshadowed any changes in intake subsequent to septal surgery. DBB lesions given after a preoperative baseline resulted in a variable duration of increased intake, with only two of six Ss showing sustained increase until sacrifice. All Ss with $\mathrm{DBB}$ lesions given after either $\mathrm{AS}$ or PS lesions, however, maintained a mean daily intake of from one to two multiples of the preoperative baseline until sacrifice. The pattern of intake after DBB lesions generally included 2-5 days of fourfold water intake whether the lesions followed a preoperative or a septal baseline.

The difference between the preoperative and DBB sham baselines did not approach significance. There were no differences in intake associated with structures damaged incidental to the intended lesion placements.

\section{DISCUSSION}

In support of Carey (1967), these results contradict Andres, Gentil, \& Covian (1967) by showing that an interruption of the $\mathrm{DBB}$ can produce an increase in water intake. However, there is an apparent contradiction served up by identical results of stimulation and ablation. Fisher \& Coury (1964) elicited intense drinking responses with cholinergic stimulation of the DBB. Although unconfirmed in rats, Hayward \& Smith (1963) noted a significant increase in $\mathrm{ADH}$ release with electrical stimulation of the DBB in monkeys. Carey (1969) has suggested that increased thirst resulting from lesions in structures that normally enhance $\mathrm{ADH}$ release may reflect a behavioral compensation for presumed deficits in $\mathrm{ADH}$ release. In addition, the anodal lesions employed in this study may have affected the results, which is consistent with Reynolds's (1963) suggestion that iron particles deposited by the lesioning procedure serve as foci of stimulation in incompletely lesioned structures. According to Fox (1940), the nucleus and fibers of the DBB run concurrently between its terminuses. Though the lesions in this study completely transected the DBB, a functional stimulation of the remaining post-preoptic components of the DBB may have provided a replication of the chemical stimulation study (Fisher \& Coury, 1964).

The hyperdipsia after PS lesions is in agreement with previous findings (Lubar et al, 1968). However, the increase in water intake after DBB lesions provides little insight into the mechanisms of PS hyperdipsia. Presumably, if there were an interaction between the anterior or posterior lateral septal nuclei and the $\mathrm{DBB}$, there would have occurred a differential response following $\mathrm{DBB}$ lesions preceded by septal lesions of these two loci. This interpretation is reinforced by the apparent divergency between the influence of the intact DBB (Hayward \& Smith, 1963) and that of the intact PS (Blass \& Hanson, 1970) upon fluid balance.

\section{REFERENCES}

ANDRES, N. V., GENTIL, C. G., \& COVIAN, M. R. Alterations in sodium chloride and water intake after septal lesions in the rat. Physiology \& Behavior, $1967,2,167-170$.

BLASS, E. M., \& HANSON, D. G. Primary hyperdipsia in the rat following septal lesions. Joumal of Comparative \& Physiological Psychology, 1970, 70, 87-93.

CAREY, R. J. Independence of effects of septal ablations on water intake and response inhibition. Psychonomic Science, $1967,8,3-4$.

CAREY, R. J. A further localization of inhibitory deficits resulting from septal ablation. Physiology \& Behavior, 1968, 3, 645-649.

CAREY, R. J. Contrasting effects of anterior and posterior septal injury on thirst motivated behavior. Physiology \& Behavior, 1969, 4, 759-764.

DAITZ, H. M., \& POWELL, T. P. S. Studies of the connexions of the fornix system. Journal of Neurology, Neurosurgery, \& Psychiatry, 1954, 17, 75-82.

FISHER, A. E., \& COURY, J. N. Cholinergic tracing of a central neural circuit underlying the thirst drive. Science, 1961, 138, 691-693.

FOX, C. A. Certain basal telencephalic centers in the cat. Journal of Comparative Neurology, 1940, 72, 1-62.

GUZMAN-FLORES, C., ALGARAZ, M., \& FERNANDEZ-GUARDIOLA, A. Rapid procedure to localize electrodes in experimental neurophysiology. Boletin del Institute de Estudios Medicos y Biologicos (Mexico), 1963, 16, 29-31.

HAYWARD, J. N., \& SMITH, W. K Influence of limbic system on neurophypophysis. Archives of Neurology, 1963, 9, 171-177.

KONIG, J. F. R., \& KLIPPEL, R. A. The rat brain, a stereotaxic atlas. Baltimore: Williams \& Wilkins, 1963.

LUBAR, J. F., BOYCE, B. A., \& SCHAEFER, C. F. Etiology of polydipsia and polyuria in rats with septal lesions. Physiology \& Behavior, 1968, 3, 289-292.

RAISMAN, G., COWAN, W. M., \& POWELL, T. P. S. An experimental analysis of the efferent projection of the hippocampus. Brain, 1966, 89, 83-108.

RANSON, S. W., FISCHER, C., \& I $\mathbf{N}$ G R A M , W. $\mathbf{R} . \quad \mathbf{T} \mathbf{h}$ hypothalamico-hypophyseal mechanism in diabetes insipidus. In The pituitary gland. Baltimore: William \& Wilkins, 1938 .

REYNOLDS, R. W. Ventromedial hypothalamic lesions without hyperphagia. American Journal of Physiology, 1963, 204, 60-62. 